NEWS

\title{
Model response to Chile quake?
}

\section{Experts debate how much emergency-response planners should rely on tsunami forecasts.}

Moments after a magnitude- 8.8 earthquake rocked Chile this weekend, a tsunami began to sweep across the Pacific Ocean at hundreds of kilometres per hour. And within 2 hours, scientists had determined that coastal communities beyond Chile probably had little to fear.

Yet around the Pacific, from Hawaii to Japan, authorities ordered extensive evacuations. To some tsunami experts the response was no more than prudent. Others think that it was a costly overreaction. "The warning system worked well in terms of trustworthiness of forecast, but its implementation had large loopholes," says Costas Synolakis, a tsunami expert at the University of Southern California, Los Angeles.

Events in Chile, where the earthquake has claimed more than 700 lives, showed the value of a timely tsunami warning. Despite the enormity of the quake - the fifth-strongest since 1900 - the Chilean Navy, responsible for tsunami warnings, failed to issue an immediate alert. Within 34 minutes, destructive waves had hit the coastal city of Valparaíso, sweeping away buildings and people. The number of casualties there is unknown - but the Chilean minister of defence, Francisco Vidal, says that without warnings issued by local authorities and harbour officials acting on their own, many more lives would have been lost.

Tsunami forecasters were already trying to work out what would happen next. Burak Uslu, a tsunami modeller with the Pacific Marine and Environmental Laboratory (PMEL) in Seattle, Washington, used a mathematical model called Method of Splitting Tsunami, developed with Synolakis and Vasily Titov of the PMEL, to forecast when waves would arrive, how high they would be and how much dry land would be flooded. It was the first time that the model had been applied to a big tsunami in the Pacific.

About 2 hours after the quake, the tsunami passed the first of the Pacific's network of monitoring buoys, which recorded a wave onequarter of the height of the 2004 Indian Ocean tsunami. When Uslu used the buoy data to refine the model's predictions (see 'Catching a wave'), he found that most of the tsunami energy would pass between Tahiti and Hawaii and continue on to Japan, and that Hawaiian beaches could be flooded up to a height of 1.2 metres. Around the same time, however, the US Pacific Tsunami Warning Center (PTWC) in Ewa Beach, Hawaii,

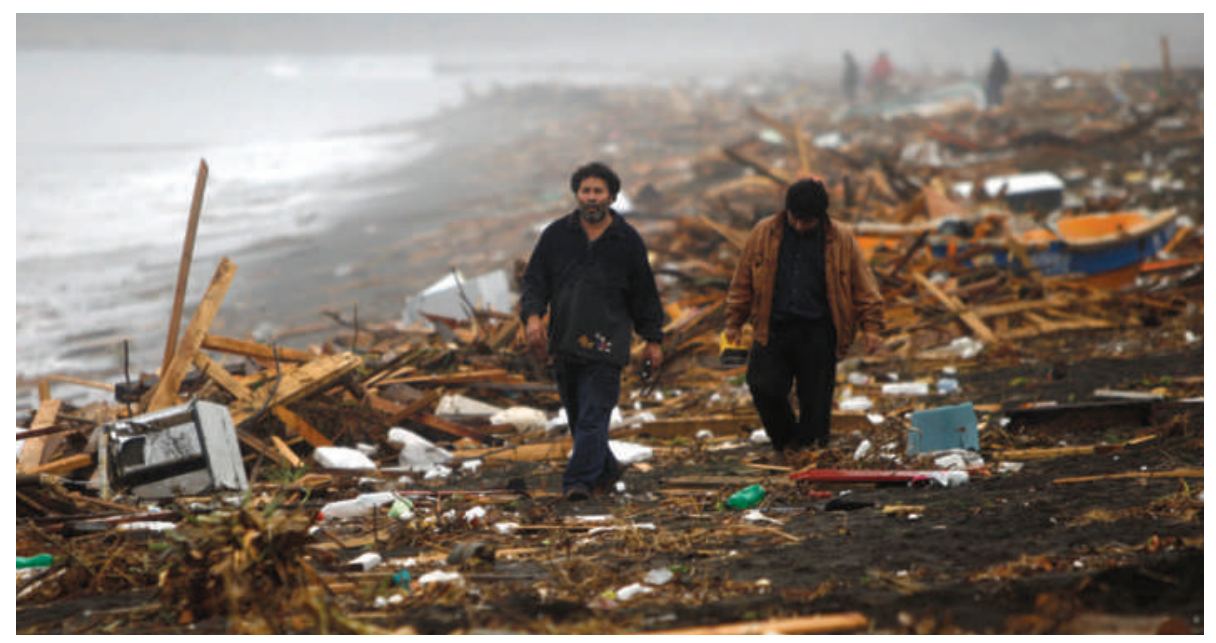

Waves caused by a magnitude- 8.8 earthquake flattened coastal regions in Chile.

\section{Unmanned planes take wing for science}

Later this month a remote-controlled aircraft is scheduled to take off from the Mojave Desert in California and veer west over the Pacific Ocean. The Global Hawk, a slim-winged, highflying jet, was designed for military reconnaissance and tested in both Iraq and Afghanistan. But this time the plane will fly for science.

Guided by pilots at NASA's Dryden Research Center, north of Los Angeles, the plane will measure concentrations of ozone, aerosols and various trace gases along a 15,000-kilometre loop around Hawaii. At the same time, atmospheric scientists hope that the drone's flight will usher in an era of unmanned scientific aircraft that can probe parts of the sky normally inaccessible to manned planes.

During the past two decades, several teams have developed and tested remote-controlled science planes, and NASA already flies the smaller Predator B - also of military origin - over western US wildfires. Drones never caught on as serious research tools, in part because they could carry so little compared with manned planes. But the Global Hawk is larger and much more capable than its predecessors, lifting a payload of around 900 kilograms to a height of nearly 20,000 metres and covering a distance of some 20,000 kilometres.

That combination "can't even be approached with any other aircraft", says David Fahey, a principal investigator with the drone project at the National Oceanic and Atmospheric Administration (NOAA) in Boulder, Colorado. "Scientists don't really know how to use a platform like this, because we've never had one. You kind of have to let your imagination be unbridled for a bit, and then you rein it back in."

In particular, the Global Hawk will give scientists the ability to stay in the stratosphere for hours, collecting samples in this key region where ozone is being destroyed. The manned ER-2 can tap the lower stratosphere, but it can't fly as far as the Global Hawk or remain up for as long, says Paul Newman, the scientist at NASA's Goddard Space Flight Center in Greenbelt, Maryland, who is leading this month's mission with Fahey. "Whenever you use these planes it always seems as if the thing that you really want to sample is about 1,000 miles farther than you can go."

Flying instruments on the Global Hawk isn't cheap or easy. NASA charges the same price - US $\$ 3,500$ per hour - to use the Global Hawk as for various manned aircraft. And although staying in the air for long periods offers many advantages, Fahey says that the team has had to figure out the logistics of rotating 
CATCHING A WAVE

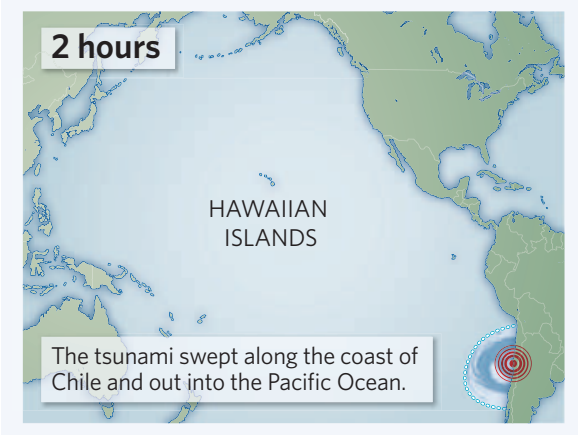

issued an ocean-wide tsunami warning.

Synolakis contends that the PTWC was divided on how to respond to the forecasts after all, a tsunami triggered by the largest-ever recorded earthquake, which struck Chile in 1960, had killed 61 people in Hilo, Hawaii. But this is denied by Charles McCreery, director of the PTWC: "I heard no dissent in our office."

The PTWC decided that tsunami alerts should be kept in place despite the forecasts of relatively little impact outside Chile. Many thousands of people were evacuated from beaches and low-lying land in Hawaii and parts of Japan, and Californian beach-goers and communities were held on standby. "We were not going to gamble with people's lives," says McCreery. He maintains that Hawaii had a good chance of sustaining damage and points out that the Marquesas Islands in the south Pacific were hit by waves that were 4 metres from crest to trough.

In time, the model's predictions would be
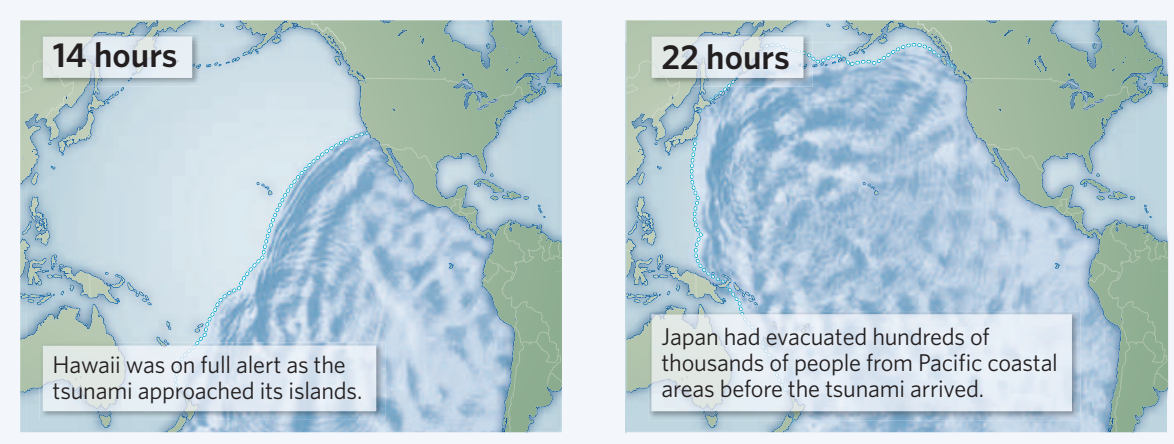

vindicated by events around the Pacific. When the waves arrived in Hawaii, they were little higher than the normal surf, whereas coastal communities in northern Japan, 17,000 kilometres from the earthquake zone, faced modest flooding — the worst impact outside Chile.

Scientists think that this week's tsunami was milder than the Indian Ocean event because the fault that slipped lay beneath a relatively shallow part of the ocean, and therefore displaced a smaller volume of water. The geometry of the fault and the way it ruptured probably also helped to limit the severity of the tsunami. "Had the ground ruptured a bit further north, Hawaii would had been severely hit," says Synolakis.

McCreery admits that the PTWC took a conservative approach to what the model was telling them. "We'll be looking at this very hard over the next few months, and longer, to see what improvements can be made," he says. As confidence grows in the model, experts may be more prepared to cancel tsunami warnings earlier, he adds. Although serial false alarms can make people complacent about the threat of a tsunami, McCreery says that occasional evacuations can actually increase people's confidence that the system is working.

Jörn Lauterjung, a tsunami expert at the German Research Centre for Geosciences in Potsdam who oversees the German-Indonesian tsunami early-warning system, agrees that the PTWC made the right decision. If an earthquake of similar magnitude strikes the Indian Ocean region, he says, authorities should take the same action. But Synolakis argues that the increasing reliability of tsunami forecasts allows emergency planners to order evacuation only when necessary. "The authorities in charge need to listen to science," says Synolakis. "Every ounce of extra prevention is counterproductive as it reduces the overall credibility of the system."

Quirin Schiermeier crews of scientists to monitor equipment during a 30-hour flight.

Chris Naftel, who manages the programme for NASA, saw the potential of the military reconnaissance drones in 2005, when the Air Force was decommissioning seven Global Hawk prototypes. Naftel secured two of the prototypes in 2007 and a third last year for free. The agency signed an agreement with the plane's producer, Northrop Grumman in Los Angeles, to help convert the aircraft, install new communications equipment, train employees and build an operations centre.

During the summer, a team of NASA scientists will deploy the Global Hawk to monitor Atlantic storms, hoping to peer inside them as some develop from tropical

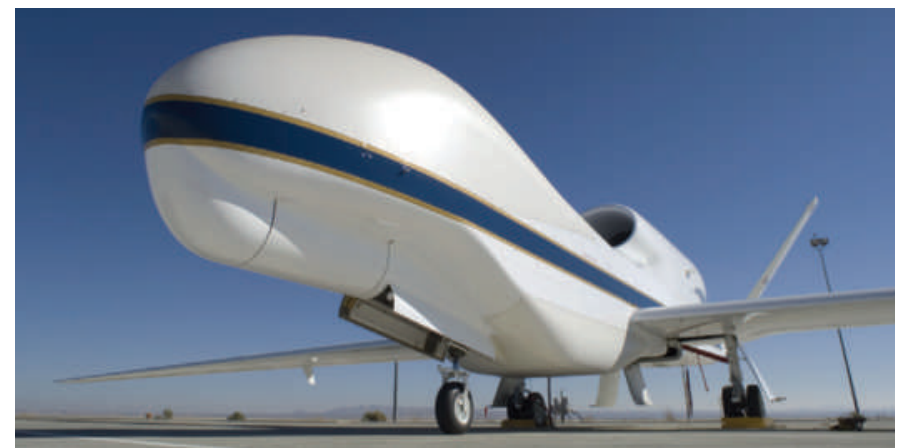

Nose for science: the Global Hawk will gather data during 30-hour flights.

disturbances into hurricanes. Multiple teams are developing other research missions, and NASA is now working on a mobile communications centre that will give the aircraft truly global coverage.

With Global Hawk about to start its science runs, support is growing for unmanned research planes. Research Council last month called unmanned vehicles an "extremely exciting complement" to NASA's current aerial fleet. And NOAA is pondering whether to develop its own fleet of science drones. A report from the US National
David Parrish, a colleague of Fahey's at NOAA who conducts intensive atmospheric research campaigns with a converted passenger aircraft, the $\mathrm{P3}$, emphasizes that manned missions are unlikely to end any time soon. His team loads a P3 with so much instrumentation that the plane, which is designed to hold 80-90 passengers, can seat just five or six scientists.

"It's very difficult to develop instruments with the needed precision and accuracy, yet small enough to fly on these unmanned platforms," Parrish says. He adds, however, that "the atmosphere is so big and so complex" that there is certainly room for both types of aircraft. Jeff Tollefson 